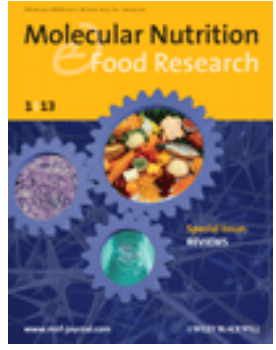

\title{
Induction of autophagy and activation of SIRT-1 deacetylation mechanisms mediate neuroprotection by the pomegranate metabolite urolithin A in BV2 microglia and differentiated 3D human neural progenitor cells
}

\begin{tabular}{|r|l|}
\hline Journal: & Molecular Nutrition and Food Research \\
\hline Manuscript ID & mnfr.201801237.R2 \\
\hline Wiley - Manuscript type: & Research Article \\
\hline Dute Submitted by the & n/a \\
\hline Complete List of Authors: & $\begin{array}{l}\text { Velagapudi, Ravikanth; University of Huddersfield, Division of Pharmacy; } \\
\text { University of North Carolina at Chapel Hill School of Medicine } \\
\text { Lepiarz, Izabela; University of Huddersfield, Division of Pharmacy } \\
\text { Elbakoush, Abdelmeneim; University of Huddersfield, Division of } \\
\text { Pharmacy } \\
\text { Katola, Folashade; University of Huddersfield, Division of Pharmacy } \\
\text { Bhatia, Harsharan; University of Freiburg Medical School; Klinikum der } \\
\text { Universität München } \\
\text { Fiebich, Bernd; University of Freiburg Medical School } \\
\text { Olajide, Olumayokun; University of Huddersfield, Division of Pharmacy }\end{array}$ \\
\hline Keywords: & $\begin{array}{l}\text { Urolithin A, Neuroprotective, Autophagy, SIRT-1, Microglia, 3D human } \\
\text { neural progenitor cells, Neuroinflammation }\end{array}$ \\
\hline & \\
\hline
\end{tabular}

\section{SCHOLARONE" \\ Manuscripts}




\section{Graphical Abstract}

Urolithin $A$ is a gut-derived metabolite of fruits such as pomegranate. In this study we investigated molecular mechanisms involved in the neuroprotective actions of this compound. The outcome of the experiments showed that urolithin A produced inhibition of neuroinflammation and amyloid beta neurotoxicity by activating DNA deacetylation mechanisms and induction of autophagy in BV2 microglia and human neural progenitor cells. 


\section{Bacterial Lipopolysaccharide}
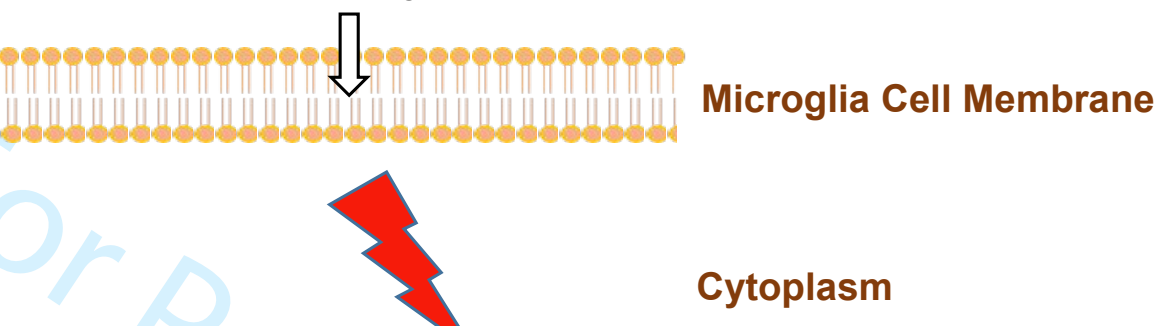

NF-אB Activation \& Nuclear Translocation

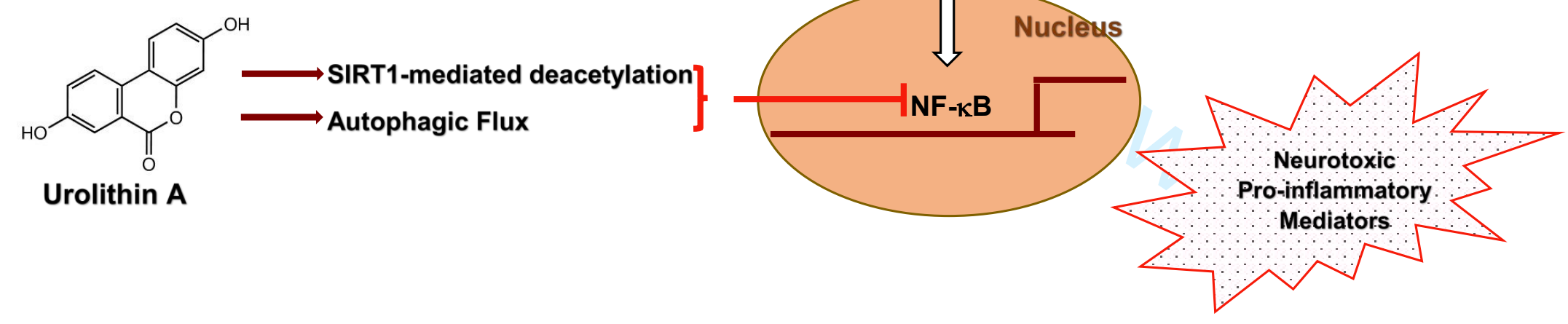




\section{Induction of autophagy and activation of SIRT-1 deacetylation mechanisms mediate neuroprotection by the pomegranate metabolite urolithin A in BV2 microglia and differentiated 3D human neural progenitor cells}

Ravikanth Velagapudi ${ }^{1,2}$, Izabela Lepiarz ${ }^{1}$, Abdelmeneim El-Bakoush ${ }^{1}$, Folashade O Katola ${ }^{1}$, Harsharan Bhatia ${ }^{3,4}$, Bernd L. Fiebich ${ }^{3}$, Olumayokun Olajide $^{1^{*}}$

${ }^{1}$ Department of Pharmacy, School of Applied Sciences, University of Huddersfield, Huddersfield, HD1 3DH, United Kingdom

2 Present address: Neuroscience Center, Department of Cell Biology and Physiology, University of North Carolina School of Medicine, Chapel Hill, North Carolina, USA. ${ }^{3}$ Neurochemistry and Neuroimmunology Research Group, Department of Psychiatry and Psychotherapy, Medical Center-University of Freiburg, Hauptstrasse 5, 79104, Freiburg, Germany

${ }^{4}$ Present address: Institute for Stroke and Dementia Research, Klinikum der Universität München, Ludwig Maximilians University, Munich, Germany.

\section{*Author for Correspondence}

Dr Olumayokun A Olajide

Department of Pharmacy

University of Huddersfield

Queensgate

Huddersfield, HD1 3DH

United Kingdom

Email: o.a.olajide@hud.ac.uk

Telephone: +44 (0) 1484472735 


\begin{abstract}
1. Scope

Urolithin $A$ is an anti-inflammatory and neuroprotective gut-derived metabolite from ellagitannins and ellagic acid in pomegranate, berries and nuts. We investigated the roles of SIRT-1 and autophagy in the neuroprotective activity of urolithin A.
\end{abstract}

\title{
2. Methods and results
}

Analyses of culture supernatants from lipopolysaccharide-stimulated BV2 microglia showed that urolithin $\mathrm{A}(2.5-10 \mu \mathrm{M})$ produced significant reduction in the production of nitrite, tumour necrosis factor (TNF) $\alpha$ and interleukin (IL)-6. Anti-inflammatory effect of the compound was reversed in the presence of sirtuin (SIRT)-1 and the autophagy inhibitors EX527 and chloroquine, respectively. Protein analyses revealed reduction in p65 and acetyl-p65 protein. Treatment of BV2 microglia with urolithin A resulted in increased SIRT-1 activity and nuclear protein, while induction of autophagy by the compound was demonstrated using autophagy fluorescent and autophagy LC3 HiBiT reporter assays. Viability assays revealed that urolithin A produced neuroprotective effect in APPSwe-transfected ReNcell VM human neural cells, which was reversed in the presence of EX527 and chloroquine. Increase in both SIRT-1 and autophagic activities were also detected in these cells following treatment with urolithin $\mathrm{A}$.

\section{Conclusions}

We propose that SIRT-1 activation and induction of autophagy are involved in the neuroprotective activity of urolithin $A$ in brain cells. 


\section{Introduction}

Neuroinflammation is progressively becoming a critical process in many neurodegenerative diseases including Alzheimer's (AD) and Parkinson's diseases (PD). Neuroinflammation is activated by mechanisms such as oxidative stress and activation of brain resident macrophages known as microglia[1]. Furthermore, mediators, such as pro-inflammatory cytokines, released during neuroinflammation are critical in neurodegeneration ${ }^{[1]}$.

Sirtuin-1 (SIRT-1), an NAD+-dependent class III histone deacetylase, is known to play a significant role in suppressing the release of pro-inflammatory cytokines ${ }^{[2,3]}$. In microglia, over-expression of SIRT-1 has been demonstrated to inhibit microglia activation $^{[4]}$. Furthermore, the SIRT-1 activator resveratrol has been reported to inhibit neuroinflammation in LPS-activated rat primary microglia[5] and in cultured astrocytes $^{[6]}$. These observations were further confirmed by recent findings which have shown that SIRT-1 activation is neuroprotective against neuronal apoptosis, neuroinflammation and oxidative stress ${ }^{[7]}$. Autophagy is a catabolic process that is critical in the degradation of cytoplasmic proteins in multicellular organisms. Several lines of evidence have linked autophagy to neuroinflammation ${ }^{[8]}$ as well as to neurodegeneration [9]. Consequently, pharmacological modulation of brain SIRT-1 and autophagy with nutritional factors is a promising strategy in neurodegenerative diseases.

Urolithins are bioavailable metabolites that are produced by the human gut microbiota from ellagitannins and ellagic acid found in food products such as pomegranate, berries, and nuts. Several biological activities have been reported for the urolithins; they were reported to inhibit inflammation in vivo in rat model of inflammatory bowel disease ${ }^{[10]}$, as well as in vitro in human colonic fibroblasts ${ }^{[11]}$, RAW 264.7 murine macrophages ${ }^{[12,13]}$ and BV2 microglia[14]. Studies by DaSilva et al. have also shown that urolithins inhibited neuroinflammation in LPS-stimulated BV2 microglia and protected SH-SY5Y cells from oxidative stress-induced toxicity[15]. Furthermore, urolithin A was shown to extend the lifespan of $C$. elegans and improves muscle function in mice through upregulation of mitophagy[16]. In this study, we aimed to establish the roles of SIRT-1-mediated deacetylation and autophagic flux in the neuroprotective activity of urolithin $A$, the most active urolithin. 


\section{Materials and methods}

\subsection{Cell culture and treatments}

The BV2 mouse microglia cell line (ICLC ATL03001; Interlab Cell Line Collection, Banca Biologica e Cell Factory, Italy) was cultured in RPMI1640 medium with 10\% fetal bovine serum, $2 \mathrm{mM} \mathrm{L-glutamine,} 1 \mathrm{mM}$ sodium pyruvate, $100 \mathrm{U} / \mathrm{ml}$ penicillin and $100 \mathrm{mg} / \mathrm{ml}$ streptomycin in a $5 \% \mathrm{CO}_{2}$ incubator.

HEK293 (ECACC 85120602) cells were obtained from the European Collection of Cell Cultures (ECCAC) (Salisbury, UK) and were cultured in MEM-eagle's medium (Thermo Scientific). MEM medium was supplemented with 10\% FBS, 2 mM Lglutamine, $1 \mathrm{mM}$ sodium pyruvate, $2 \mathrm{mM} \mathrm{L-} \mathrm{glutamine,} 100 \mathrm{U} / \mathrm{ml}$ penicillin, and 100 $\mathrm{mg} / \mathrm{ml}$ streptomycin in a $5 \% \mathrm{CO} 2$ incubator.

Immortalised neural progenitor cells (ReNcell VM cells) were acquired commercially from Millipore (Hertfordshire, UK) and maintained as earlier described[17]. Cells were differentiated by replacing the culture medium with ReNcell NSC maintenance medium without the growth factors EGF and FGF-2 for 14 days. Differentiation into neurons was confirmed by immunocytochemical staining for ßIII-tubulin and MAP2[17] (Supplementary Figure S1-S3).

Urolithin A (Santa Cruz), EX527 (Sigma) and chloroquine (Arcos Organics) were prepared in dimethylsulfoxide (DMSO) for pharmacological experiments. The percentage of DMSO in cell culture was $0.2 \%$. For all experiments, $5 \times 10^{4} \mathrm{cells} / \mathrm{ml}$ were seeded out in culture plates.

\subsection{Dosage information}

Treatment of these cells with urolithin A $(2.5-10 \mu \mathrm{M})$ with LPS stimulation for $24 \mathrm{~h}$ did not affect cell viability (Supplementary Figure S4).

\subsection{Determination of pro-inflammatory mediator release}

$\mathrm{BV} 2$ microglia were pre-treated with urolithin $\mathrm{A}(2.5-10 \mu \mathrm{M})$ or vehicle $(0.2 \% \mathrm{DMSO})$. After $30 \mathrm{~min}$, cells were stimulated with LPS $(100 \mathrm{ng} / \mathrm{ml})$ for $24 \mathrm{~h}$. Levels of nitrite in culture medium were determined using the Griess reagent (Promega), according to the manufacturer's instructions. Production of TNFa and IL-6 was determined using mouse ELISA kits (Biolegend), according to the manufacturer's instructions.

Detection limits were $1.5 \mathrm{pg} / \mathrm{ml}$ and $2 \mathrm{pg} / \mathrm{ml}$ for TNF $\alpha$ and IL-6, respectively. These 
experiments were also carried out in cells treated with SIRT-1 inhibitor (EX527; $1 \mu \mathrm{M})$ or autophagy inhibitor (chloroquine; $40 \mu \mathrm{M}) 30$ min before addition of urolithin $\mathrm{A}(10 \mu \mathrm{M})$ and stimulation with LPS (100 $\mathrm{ng} / \mathrm{ml})$.

\subsection{Transfection of ReNcell VM human neural stem cells with APPSwe plasmids}

Differentiated ReNcell VM cells were transfected with APPSwe plasmids as described and reported earlier[17]. Transfected cells were treated with urolithin $A$ (2.5-10 $\mu \mathrm{M})$ for $48 \mathrm{~h}$. Cell viability was evaluated using MTT and LDH viability assays. Levels of $A \beta_{42}$ in culture medium of cells treated with urolithin $A$ for 14 days were determined by using a human $A \beta_{42}$ ELISA kit (Life Technologies). Cell viability experiments were also carried out in cells treated with SIRT-1 inhibitor (EX527; $1 \mu \mathrm{M}$ ) or autophagy inhibitor (chloroquine; $40 \mu \mathrm{M}$ ) $30 \mathrm{~min}$ prior to treatment with urolithin $\mathrm{A}(10 \mu \mathrm{M})$.

\subsection{Immunofluorescence microscopy}

Immunofluorescence detection for NF-кBp65, acetyl-p65, SIRT-1, nestin, ßIII-tubulin, and MAP2 proteins was carried with Alexa Fluor 488-conjugated donkey anti rabbit IgG secondary antibody (Life Technologies; 1:500) and images were obtained using EVOS ${ }^{\circledR}$ FLoid $^{\circledR}$ cell imaging station as described elsewhere ${ }^{[15,16]}$.

\subsection{In-cell western for quantitative immunocytochemistry measurement of protein levels}

This is a rapid method for quantification of proteins in cells. The method is similar to immunoblotting and immunocytochemistry and combines the specificity achieved with immunoblotting with the quantification capability of ELISA. BV2 microglia were seeded into a 96-well plate at a density of $5 \times 10^{4}$ cells $/ \mathrm{ml}$. Thereafter, cells were treated with urolithin $A(2.5-10 \mu \mathrm{M})$, and then stimulated with LPS (100 ng/ml) for 60 min. Cell fixation was achieved with $8 \%$ paraformaldehyde solution, followed by overnight incubation with primary antibodies. The following antibodies were used:

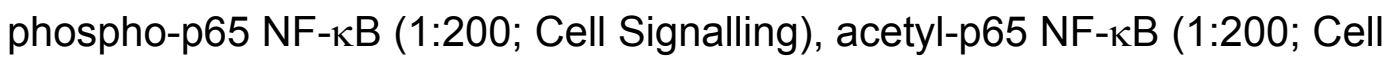
Signalling). This was followed by incubation with anti-rabbit HRP secondary antibody for $2 \mathrm{~h}$ at room temperature. Then, $100 \mu \mathrm{L} \mathrm{HRP}$ substrate was added to the plate 
and signal measured at 450nm with a microplate reader. Readings were normalised with Janus Green stain (Abcam).

\subsection{SIRT-1 ELISA and activity assay}

Cultured BV2 microglia or differentiated ReNcell VM human neural cells were treated with urolithin $\mathrm{A}(2.5-10 \mu \mathrm{M})$ for $24 \mathrm{~h}$. Thereafter, nuclear extracts were collected for analysis of SIRT-1 using either mouse or human SIRT-1 ELISA kit (Abcam), according to the manufacturer's instructions. SIRT-1 activity in cultured cells was also evaluated using the luminescent SIRT-Glo ${ }^{\text {TM }}$ Assay (Promega), according to the manufacturer's instructions and described earlier ${ }^{[18,19] .}$

\subsection{Autophagy fluorescent assay}

This experiment was carried out using an autophagy assay kit (Sigma), which provides a simple and direct approach for detecting autophagy in cells by employing a fluorescent autophagosome marker. BV2 or differentiated ReNcell VM cells were treated with urolithin $\mathrm{A}(2.5-10 \mu \mathrm{M})$ for $24 \mathrm{~h}$. Thereafter, medium was removed and the cells were incubated with autophagosome detection reagent at $37^{\circ} \mathrm{C}$ with $5 \%$ $\mathrm{CO}_{2}$ for $1 \mathrm{~h}$. Fluorescence intensity $\left(\lambda_{\mathrm{ex}}=360 / \lambda_{\mathrm{em}}=520 \mathrm{~nm}\right)$ was measured using a Polarstar Optima Plate microplate reader.

\subsection{Autophagy LC3 HiBiT reporter assay}

The autophagy LC3 HiBiT reporter vector (Promega) has a HiBiT tag and contains a sequence encoding the MAP1LC3B gene. On induction of autophagy, LC3 reporter proteins are trapped in autophagosomes and degraded. HEK293, BV2 microglia, or differentiated ReNcell VM cells were transfected with the autophagy LC3 HiBiT reporter vector using Fugene 6 transfection reagent (Promega) and incubated for $16 \mathrm{~h}$ at $37^{\circ} \mathrm{C}$ in $5 \% \mathrm{CO}_{2}$. Thereafter, transfected cells were plated in white 96-well plates and treated with urolithin $A(2.5-10 \mu \mathrm{M})$ for $6 \mathrm{~h}$. Then, $100 \mu \mathrm{l}$ of Nano-Glo ${ }^{\circledR}$ $\mathrm{HiBiT}$ lytic reagent (Promega) was added to each well and the samples were mixed using an orbital shaker for 2 min. Luminiscence was measured on a Polarstar Optima Plate microplate reader. 


\subsection{Statistical analysis}

Values of all experiments were represented as a mean \pm SEM of at least 3 experiments. Values were compared using one-way ANOVA followed by a post hoc Tukey test.

\section{Results and discussion}

\subsection{Urolithin A inhibits neuroinflammation and acetylation of NF-kB in LPS-activated BV2 microglia}

Firstly, we were interested in establishing an anti-inflammatory activity for urolithin A in LPS-activated BV2 microglia. Our results showed that treatment with LPS $(100 \mathrm{ng} / \mathrm{ml})$ resulted in a significant $(p<0.001)$ elevation in the levels of TNFa, IL-6, and nitrite in cell culture supernatants (Figure $3 \mathrm{~A}$ ). However, pre-treatment with urolithin $A(2.5-10 \mu M)$ resulted in a significant $(p<0.01)$ and concentrationdependent reduction in the release of TNFa and nitrite. Levels of IL-6 was also decreased significantly and but not in a concentration-dependent manner. Inhibition of neuroinflammation by the compound was further confirmed using quantitative in cell ELISA and immunofluorescence experiments showing inhibition of LPS-induced phosphorylation (Figure 2B) nuclear accumulation (Supplementary Figure S5A) of $N F-\kappa B$ in BV2 cells. Similar anti-inflammatory effects have been reported for urolithin A and other urolithins in BV2 microglia[14, 15].

It has been suggested that phase II glucuronide and sulfate conjugate metabolites of urolithins may be more physiologically relevant than the urolithins in order to produce pharmacological actions in vivo ${ }^{[20]}$. However, in addition to demonstrating in vivo neuroprotective activity of urolithins, Yuan et al used in silico computational studies to predict blood-brain barrier permeability of the compounds ${ }^{211)}$. The relative in vivo neuroprotective activities of urolithins and their phase II metabolites therefore warrant further investigation.

In neuroinflammation, activation of $\mathrm{NF}-\kappa \mathrm{B}$ and subsequent transcriptional regulation of pro-inflammatory genes involves post-translational modifications such as reversible acetylation of the NF-KB-p65 subunit ${ }^{[22]}$. Our investigations demonstrated that treatment with urolithin A reduced protein levels of acetyl-p65 in BV2 microglia stimulated with LPS (Figure 2C and Supplementary Figure S5B). We report here for 
the first time that inhibition of LPS-induced acetylation of p65 by urolithin $A$ is a critical mechanism in the anti-inflammatory activity of the compound, thus suggesting a role for nuclear histone deacetylation mechanisms.

\subsection{The role of SIRT-1 activation in the inhibition of neuroinflammation by urolithin A in BV2 microglia}

Sirtuins (SIRTs) are class III histone deacetylases (HDACs), and have been strongly linked to regulation of neuroinflammation and neurodegeneration ${ }^{[23,24]}$. Specifically, SIRT-1 activation prevents NF- $\mathrm{B}$ activation through mechanisms involving deacetylation of the p65 subunit ${ }^{[25]}$. Furthermore, inhibition of SIRT-1 in LPS-activated microglia has been observed to correlate with increased production of inflammatory cytokines ${ }^{[26,27] .}$

Encouraged by our results showing that urolithin A reduced protein levels of acetyl-p65 in LPS-stimulated microglia, we were interested in evaluating whether this compound produces a direct activation of SIRT-1 in BV2 microglia. ELISA experiments showed that at $2.5 \mu \mathrm{M}$ of urolithin $A$, the increase in nuclear SIRT-1 protein was not significant when compared with untreated cells (Figure 3A). However, nuclear SIRT-1 protein levels in cells treated with 5 and $10 \mu \mathrm{M}$ of the compound were significantly $(p<0.05)$ higher than the levels in untreated cells. Similarly, significant $(p<0.01)$ SIRT-1 activity was observed in BV2 cells treated with 5 and $10 \mu \mathrm{M}$ of urolithin $\mathrm{A}$ (Figure $3 \mathrm{~B}$ ). These results were further confirmed by immunofluorescence microscopy for the detection of SIRT-1 in BV2 cells (Supplementary Figure S6).

Experiments were thereafter carried out to confirm a direct involvement of SIRT-1 in the anti-inflammatory activity of urolithin A in LPS-activated microglia. In this case, BV2 cells were treated with EX527 $(1 \mu \mathrm{M})$ prior to urolithin $\mathrm{A}(10 \mu \mathrm{M})$ followed by LPS stimulation for $24 \mathrm{~h}$. Analyses of cell culture supernatants revealed that urolithin A treatment significantly $(\mathrm{p}<0.05)$ diminished LPS-induced release of TNFa, IL-6, and nitrite (Figure 4). However, in the presence of EX527, the anti-inflammatory activity observed by urolithin $A$ treatment was reversed (Figure 4). A similar outcome is depicted in Supplementary Figure S7, showing a partial reversal in the inhibition of LPS-induced nuclear accumulation of NF-кB p65 sub-unit in BV2 microglia in the presence of EX527. 
Taken together, these results show for the first time that urolithin A produces a direct activation of SIRT-1 in BV2 microglia. The outcome of these experiments also suggests that SIRT-1 is required for the anti-inflammatory activity of urolithin A in BV2 microglia. These are interesting observations as neuroprotective dietary compounds in fruits and vegetables such as kaempferol, quercetin, acacetin, apigenin, rutin and luteolin have been previously shown to produce NF- $\kappa$ B-mediated inhibition of neuroinflammation and to provide health benefits through the activation of SIRT-1 ${ }^{[28]}$. Recently, we showed that compounds such as thymoquinone and agathisflavone produced inhibition of neuroinflammation in LPS-activated BV2 microglia through mechanisms involving SIRT-1 ${ }^{[18,19]}$. There have also been reports linking SIRT-1 activation to anti-inflammatory and neuroprotective actions of resveratro|[29] further confirms our results. SIRT-1-mediated inhibition of neuroinflammation by dietary phytochemicals and their metabolites is a remarkable development with significant implications in nutritional strategies for neuroinflammation-mediated neurodegeneration in the ageing brain.

\subsection{Induction of autophagic flux contributes to inhibition of neuroinflammation by urolithin $\mathrm{A}$}

Recent reports have suggested that urolithin A increases autophagy ${ }^{[13,16]}$. We were therefore interested in evaluating whether this compound induces autophagy in BV2 microglia, and whether increasing autophagic flux contributes to its anti-inflammatory activity in LPS-activated BV2 microglia. To answer the first question, we investigated the effect of urolithin A treatment in an autophagy fluorescent assay, which is assay is based on the fluorescent activity of an autophagosome marker. Results in Figure 5A show that treatment with urolithin $\mathrm{A}(5$ and $10 \mu \mathrm{M})$ resulted in a significant $(p<0.05)$ increase in autophagic activity, when compared to untreated cells.

Next, we transfected both HEK293 and BV2 cells with the autophagy LC3 HiBiT reporter vector followed by urolithin A treatment. This approach was used due to low transfection efficiency normally observed in BV2 microglia. Results obtained from easy-to-transfect cells such as HEK293 cells are valuable in confirming the outcome of experiments with BV2 cells. As expected, results in figures $5 \mathrm{~B}$ and $5 \mathrm{C}$ show that luminescent signals from HEK293 cells were stronger than those in BV2 cells, as a result of a more efficient transfection of HEK293 cells. The differences in 
luminescence in HEK293 and BV2 microglia notwithstanding, we observed significant $(p<0.05)$ and concentration-dependent decrease in luminescent signals in both HEK293 and BV2 cells treated with urolithin $A$ in comparison to untreated control cells, thus demonstrating lower levels of the LC3 reporter as a result of treatment with the compound.

This is the first report showing that urolithin A increases autophagy in microglia and it seems to reflect earlier observations in peripheral macrophages ${ }^{[13]}$. These results as well as reports proposing a role for autophagy in inflammation in macrophages and microglia[ ${ }^{[30,31]}$ urged us to study whether increasing autophagic flux in BV2 microglia by treatment with urolithin A might contribute to its inhibitory effects on neuroinflammation. Incubation of BV2 microglia with chloroquine (40 $\mu \mathrm{M})$ followed by urolithin $\mathrm{A}(10 \mu \mathrm{M})$ prior to stimulation with LPS, resulted in a significant diminishment of the inhibition of LPS-induced release of pro-inflammatory mediators (TNFa, IL-6, and nitrite) by urolithin A (Figure 6). This observation led us to conclude that the ability of this compound to induce autophagy is a contributory factor in its ability to produce anti-inflammatory activity in BV2 microglia and in macrophages ${ }^{[13]}$. Studies have linked autophagy to neuroinflammatory events in microglia. Autophagic processes have been shown to mediate the release of pro-inflammatory cytokines such as IL-1 $\beta$ in the microglia| ${ }^{[32]}$. In addition, a Ginkgo biloba extract was shown to activate autophagy and inhibit microglia-mediated neuroinflammation in AD mouse brain model and primary microglia[33,34]. This suggests that induction of autophagy by nutritional phytochemicals may be a critical strategy in preventing neuroinflammation in brain ageing and neurodegenerative diseases.

\subsection{Urolithin A prevented neurotoxicity and A $\beta$ production in APPSwe- transfected ReNcell VM human neural cells}

The 3D human neural cell culture system is a valuable model for $A D^{[35,36]}$. We have therefore investigated the neuroprotective effects of urolithin A in these cells following transfection with the human APPSwe plasmid to produce the characteristic amyloid beta-induced neurotoxicity. Figures in S1-S3 (supplementary data) show differentiation of the ReNcell VM human neural cells into neurons as shown by immunostaining for $\beta$ III-tubulin and MAP2. Figures 7A and 7B show that transfection of differentiated ReNcell VM human neural cells with the APPSwe plasmid for $48 \mathrm{~h}$ 
resulted in significant $(p<0.001)$ reduction in cell viability with a corresponding significant $(p<0.01)$ increase in LDH released by the cells. However, in the presence of urolithin $A$, a significant $(p<0.05)$ and concentration-dependent neuroprotective activity was observed. In addition, treatment with the compound resulted in a significant $(p<0.05)$ reduction in the production of the neurotoxic amyloid beta by the cells (Figure 7C). These results are consistent with an earlier report which showed that urolithin A produced neuroprotection in SH-SY5Y neuronal cells ${ }^{[15]}$. Similar

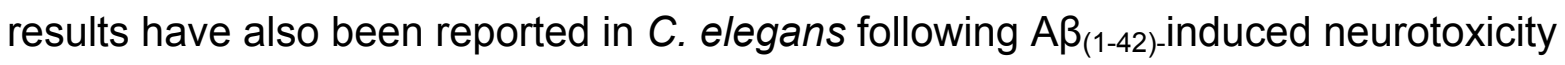
and paralysis ${ }^{[21]}$.

\subsection{Neuroprotection by urolithin A was reversed by inhibition of SIRT-1 and autophagy in APPSwe-transfected ReNcell VM human neural cells}

Further experiments demonstrated that urolithin A increases the activity and protein levels of SIRT-1 in differentiated ReNcell VM human neural cells (Figures 8A-C), and that its ability to protect neural cells from amyloid-induced toxicity is dependent on SIRT-1 (Figures 9A and 9B). This is demonstrated by a loss of neuroprotective activity in the presence of EX527. SIRT-1-mediated neuroprotection by urolithin A reflects earlier reports showing that SIRT-1 is neuroprotective against $A \beta$ plaque formation in the APPswe/PS1dE9 mouse model[37]. The observed SIRT-1-mediated neuroprotective effect of urolithin A has significant implications for its potential benefits in $A D$, as it has been reported that SIRT-1 reduced $A \beta$ levels, oxidative stress, and consequently neuronal loss ${ }^{[38]}$. The effects of urolithin A on SIRT-1 in both the microglia and neural cells clearly suggest that the compound might prevent neurodegeneration through the inhibition of neuroinflammation and $A \beta$-mediated neurotoxicity

Studies have suggested that induction of autophagy and neuroprotection involve mechanisms related to activation of SIRT-1[39]. Following our observation that urolithin A activates neuroprotective mechanisms such as activation of SIRT-1 in differentiated ReNcell VM human neural cells, we were interested in evaluating whether the compound also induces autophagy in these cells. Treating the cells with urolithin $A$ resulted in the induction of autophagy as shown in Figures 10A and 10B. We further demonstrate that in the presence of chloroquine (an autophagy inhibitor), the neuroprotective effect of urolithin A against amyloid-induced neurotoxicity was 
significantly reversed (Figures $11 \mathrm{~A}$ and $11 \mathrm{~B}$ ). These results suggest a possible link between the activation of SIRT-1 and the induction of autophagy by urolithin A and its neuroprotective effects in neural cells.

\section{Concluding remarks}

This study to our knowledge shows for the first time that SIRT-1 activation and induction of autophagy are two potentially linked mechanisms involved in the antiinflammatory activity of urolithin A in LPS-activated BV2 microglia. These mechanisms also determine the neuroprotective activity of the compound in a 3D model of AD. It is not currently clear if autophagic induction and SIRT-1 activation by this compound are coupled or if they contribute independently to the neuroprotective effects of urolithin A in microglia and neurons.

\section{Acknowledgements}

This study was funded by the University of Huddersfield through the University Research Funds (URF)/ International Exchange awarded to Dr Olumayokun Olajide. 


\section{References}

1. R. Niranjan, Neurochem Int. 2018, 120, 20.

2. J.W. Hwang, H. Yao, S. Caito, I.K. Sundar, I. Rahman, Free Radic. Biol. Med. 2013, 61, 95.

3. Q.Q. Lin, Y.W. Geng, Z.W. Jiang, Z.J. Tian, Life Sci. 2017, 170, 100.

4. L. Li, Q. Sun, Y. Li, Y. Yang, Y. Yang, T. Chang, M. Man, L. Zheng, J Mol Neurosci. 2015, 56, 858.

5. E. Candelario-Jalil, A.C. de Oliveira, S. Gräf, H.S. Bhatia, M. Hüll, E. Muñoz, B.L. Fiebich, J Neuroinflammation 2007, 4, 25.

6. X. Lu, L. Ma, L. Ruan, Y. Kong, H. Mou, Z. Zhang, W. Wang, J.M. Wang, Y. Le, J Neuroinflammation 2010, 7, 46.

7. S. Bastianetto, C. Ménard, R. Quirion, Biochim Biophys Acta. 2015, 1852, 1195.

8. M.E. Bosch, T. Kielian, Front. Neurosci. 2015, 9, 417.

9. J.H. Liang, J.P. Jia, Neurosci Bull 2014, 30, 308.

10. M. Larrosa, A. González-Sarrías, M.J. Yáñez-Gascón, M.V. Selma, M. AzorínOrtuño, S. Toti, F. Tomás-Barberán, P. Dolara, J.C. Espín, J Nutr Biochem. 2010, $21,717$.

11. A. González-Sarrías, M. Larrosa, F.A. Tomás-Barberán, P. Dolara, J.C. Espín, Br J Nutr. 2010, 104, 503.

12. J.P. Piwowarski, A.K. Kiss, S. Granica, T. Moeslinger, Mol Nutr Food Res. 2015, 59, 2168.

13. Y.D. Boakye, L. Groyer, E.H. Heiss, Biochim Biophys Acta Gen Subj. 2018, 1862, 61.

14. J. Xu, C. Yuan, G. Wang, J. Luo, H. Ma, L. Xu, Y. Mu, Y. Li, N.P. Seeram, X. Huang, L. Li, J Agric Food Chem. 2018, 66, 571.

15. N.A. DaSilva, P.P. Nahar, H. Ma, A. Eid, Z. Wei, S. Meschwitz, N.H. Zawia, A.L. Slitt, N.P. Seeram, Nutr Neurosci. 2019, 22, 185.

16. D. Ryu, L. Mouchiroud, P.A. Andreux, E. Katsyuba, N. Moullan, A.A Nicolet-DitFélix, E.G. Williams, P. Jha, G. Lo Sasso, D. Huzard, P. Aebischer, C. Sandi, C. Rinsch, J. Auwerx, Nat. Med. 2016, 22, 879.

17.R. Velagapudi, A. El-Bakoush, O.A. Olajide, Mol Neurobiol. 2018, 55, 8103.

18. R. Velagapudi, O.O. Ajileye, U. Okorji, P. Jain, M.A. Aderogba, O.A. Olajide, Phytother Res. 2018, 32, 1957. 
19. R. Velagapudi, A. El-Bakoush, I. Lepiarz, F. Ogunrinade, O.A. Olajide, Mol Cell Biochem. 2017, 435, 149.

20. F.A. Tomás-Barberán FA, A. González-Sarrías A, R. García-Villalba R, M.A. Núñez-Sánchez, M.V. Selma, M.T. García-Conesa, J.C. Espín, Mol Nutr Food Res. 2017, 61, 1.

21. T. Yuan, H. Ma, W. Liu, D.B. Niesen, N. Shah, R. Crews, K.N. Rose, D.A. Vattem, N.P. Seeram, ACS Chem Neurosci. 2016, 7, 26.

22. H. Yang H, W. Zhang, H. Pan, H.G. Feldser, E. Lainez, C. Miller, S. Leung, Z. Zhong, H. Zhao, S. Sweitzer, T. Considine, T. Riera, V. Suri, B. White, J.L. Ellis, G.P. Vlasuk, C. Loh, PLoS One. 2012; 7, e46364.

23. H. Jęśko, P. Wencel, R.P. Strosznajder, J.B. Strosznajder, Neurochem Res. $2017,42,876$.

24. L. Rizzi L, M. Roriz-Cruz, Neuropeptides 2018, 71, 54.

25. L. Yang, J. Zhang, C. Yan, J. Zhou, R. Lin, Q. Lin, W. Wang, K. Zhang, G. Yang, X. Bian, A. Zeng, Cell Physiol Biochem 2012, 30, 1287.

26. S.H. Cho, J.A. Chen, F. Sayed, M.E. Ward, F. Gao, T.A. Nguyen, G. Krabbe, P.D. Sohn, I. Lo, S. Minami, N. Devidze, Y. Zhou, G. Coppola, L. Gan, J Neurosci 2015, 35, 807.

27. J. Ye, Z. Liu, J. Wei, L. Lu, Y. Huang, L. Luo, H. Xie, Neurosci Lett 2013, 553, 72. 28. M. Ajami, H. Pazoki-Toroudi, H. Amani, S.F. Nabavi, N. Braidy, R.A. Vacca, A.G. Atanasov, A. Mocan, S.M. Nabavi, Neurosci Biobehav Rev. 2017, 73, 39.

29.B.A.Q. Gomes, J.P.B. Silva, C.F.R. Romeiro, S.M. Dos Santos, C.A. Rodrigues, P.R. Gonçalves, J.T. Sakai, P.F.S. Mendes, E.L.P. Varela, M.C. Monteiro, Oxid Med Cell Longev. 2018, 2018, 8152373.

30. J. Ye, Z. Jiang, X. Chen, M. Liu, J. Li, N. Liu, J Neurochem. 2017, 142, 215.

31.S. Schlottmann, F. Buback, B. Stahl, R. Meierhenrich, P. Walter, M. Georgieff, U. Senftleben, Mediators Inflamm. 2008, 2008, 725854.

32. J. Harris, M. Hartman, C. Roche, S.G. Zeng, A. O'Shea, F.A. Sharp, E.M. Lambe, E.M. Creagh, D.T. Golenbock, J. Tschopp, H. Kornfeld, K.A. Fitzgerald, E.C. Lavelle, J Biol Chem, 2011, 286, 9587.

33. X. Liu, W. Hao, Y. Qin, Y. Decker, X. Wang, M. Burkart, K. Schotz, M.D. Menger, K. Fassbender, Y. Liu, Brain Behav Immun 2015, 46, 121.

34. B. Gargouri, J. Carstensen, H.S. Bhatia, M. Huell, G.P.H. Dietz, B.L. Fiebich, Phytomedicine 2018, 44, 45. 
35. S.H. Choi, Y.H. Kim, M. Hebisch, C. Sliwinski, S. Lee, C. D'Avanzo, H. Chen, B. Hooli, C. Asselin, J. Muffat, J.B. Klee, C. Zhang, B.J. Wainger, M. Peitz, D.M. Kovacs, C.J. Woolf, S.L. Wagner, R.E. Tanzi, D.Y. Kim, Nature 2014, 515, 274. 36. Y.H. Kim, S.H. Choi, C. D'Avanzo, M. Hebisch, C. Sliwinski, E. Bylykbashi, K.J. Washicosky, J.B. Klee, O. Brüstle, R.E. Tanzi, D.Y. Kim, Nat Protoc. 2015, 10 , 985.

37. G. Donmez, T.F. Outeiro, EMBO Mol Med. 2013, 5, 344.

38. J.A. Godoy, J.M. Zolezzi, N. Braidy, N.C. Inestrosa Mol Neurobiol. 2014, 50, 744. 39. S.Y. Park, H.R. Lee, W.S. Lee, H.K. Shin, H.Y. Kim, K.W. Hong, C.D. Kim, PLoS One. 2016, 1, e0160620. 


\section{Figure Legends}

\section{Figure 1}

Structure of urolithin A

\section{Figure 2}

Effect of urolithin $\mathrm{A}(2.5-10 \mu \mathrm{M})$ on NF-kB-mediated pro-inflammatory mediator release in LPS-stimulated BV2 microglia. Treatment resulted in a reduction in the production of TNFa, IL-6 and nitrite in culture supernatants following incubation with LPS (100 ng/ml) for $24 \mathrm{~h}(\mathrm{~A})$. In cell western ELISA in LPS-activated BV2

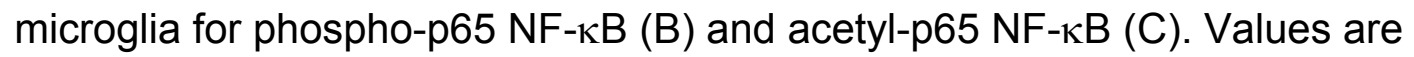
mean \pm SEM for at least 3 independent experiments $\left({ }^{* *} p<0.01 ;{ }^{* *} p<0.001\right.$, compared with LPS only; one-way ANOVA with post-hoc Tukey test).

\section{Figure 3}

Urolithin A directly activates SIRT-1 in BV2 microglia. BV2 cells were treated with urolithin $A(2.5-10 \mu \mathrm{M})$ for $24 \mathrm{~h}$. This was followed by ELISA to determine levels of SIRT-1 protein in nuclear extracts (A), luminescent SIRT-Glo assay for SIRT-1 activity in live cells $(B)$. Values are mean \pm SEM for at least 3 independent experiments (ns: not significant; ${ }^{*} p<0.05$; ${ }^{* *} p<0.01$; ${ }^{* *} p<0.001$, compared with untreated control; one-way ANOVA with post-hoc Tukey test).

\section{Figure 4}

Inhibition of neuroinflammation by urolithin A is dependent on SIRT-1. Levels of nitrite, TNF $\alpha$ and IL-6 in culture supernatants in BV2 microglia stimulated with LPS $(100 \mathrm{ng} / \mathrm{ml})$ were reduced in the presence of urolithin $\mathrm{A}(10 \mu \mathrm{M})$. However, in the presence of EX527 $(1 \mu \mathrm{M})$, anti-inflammatory activity of urolithin A was diminished. Values are mean \pm SEM for at least 3 independent experiments $\left({ }^{* *} p<0.01 ;{ }^{* * *} p<0.001\right.$ compared with untreated control. ${ }^{\theta \theta} p<0.01 ;{ }^{\theta \theta \theta} p<0.001$, compared with LPS control. \&\&p<0.01; \&\&\&p<0.001 compared with urolithin A +LPS treatment only; one-way ANOVA with post-hoc Tukey test).

\section{Figure 5}

Autophagic induction by Urolithin. Treatment of BV2 microglia resulted in induction of autophagy measured with a colorimetric autophagy assay kit $(A)$. Transfection of HEK293 cells (B) and BV2 microglia (C) with the LC3 HiBiT reporter followed by treatment with urolithin $\mathrm{A}(2.5-10 \mu \mathrm{M})$ resulted in an increase in reporter activity as measured by luminescence. Values are mean \pm SEM for at 
least 3 independent experiments (ns: not significant; ${ }^{*} p<0.05 ;{ }^{* *} p<0.001$, compared with untreated control; one-way ANOVA with post-hoc Tukey test).

\section{Figure 6}

Autophagy induction plays a role in the anti-inflammatory activity of urolithin $A$ in LPS-activated BV2 microglia. Levels of TNFa, IL-6 and nitrite in culture supernatants of BV2 microglia stimulated with LPS $(100 \mathrm{ng} / \mathrm{ml})$ were reduced in the presence of urolithin $\mathrm{A}(10 \mu \mathrm{M})$. However, in the presence of chloroquine $(40 \mu \mathrm{M})$, anti-inflammatory activity of urolithin A was diminished. Values are mean \pm SEM for at least 3 independent experiments $\left({ }^{* * *} p<0.001\right.$ compared with untreated control. ${ }^{\theta \theta \theta} p<0.001$ compared with LPS only. $\& \& \& p<0.001$ compared with urolithin A +LPS treatment; one-way ANOVA with post-hoc Tukey test).

\section{Figure 7}

Urolithin A produces neuroprotective effect in differentiated ReNcell VM human neural stem cells. Treatment of APPSwe-transfected ReNcell VM human neural stem cells with urolithin $A(2.5-10 \mu \mathrm{M})$ prevented neuronal death measured with $\operatorname{MTT}(A)$ and LDH (B) assays. This was accompanied by a reduction in the production of amyloid beta $(C)$. Values are mean \pm SEM for at least 3 independent experiments $\left({ }^{*} p<0.05 ;{ }^{* *} p<0.01 ;{ }^{* * *} p<0.001\right.$, compared with APPSwe-transfected cells; one-way ANOVA with post-hoc Tukey test).

\section{Figure 8}

Treatment of differentiated ReNcell VM human neural stem cells with urolithin A increased nuclear concentration of SIRT-1 protein (A) and increased SIRT-1 activity in live cells (B). Immunofluorescent microscopy also shows an induction in nuclear accumulation of SIRT-1 in the cells $(C)$. Values are mean \pm SEM for at least 3 independent experiments $\left({ }^{* *} p<0.01\right.$; ${ }^{* * *} p<0.001$, compared with untreated control; one-way ANOVA with post-hoc Tukey test).

\section{Figure 9}

Loss of neuroprotection by urolithin $A(10 \mu \mathrm{M})$ in the presence of EX527 $(1 \mu \mathrm{M})$ in APPSwe-transfected ReNcell VM human neural stem cells. Neural viability was measured using the MTT (A) and LDH (B) assays. Values are mean \pm SEM for at least 3 independent experiments $\left({ }^{* *} p<0.01\right.$; ${ }^{* *} P<0.001$, compared with untreated cells. ${ }^{\theta} p<0.05 ;{ }^{\theta \theta} p<0.001$, compared with APPSwe control. ${ }^{\&} \mathrm{p} p<0.01$; 
\&\&\&p<0.001, compared with urolithin A + APPSwe control; one-way ANOVA with post-hoc Tukey test).

\section{Figure 10}

Treatment of differentiated ReNcell VM human neural stem cells resulted in induction of autophagy measured with a colorimetric autophagy assay kit (A). Transfection of differentiated ReNcell VM human neural stem cells with the LC3 $\mathrm{HiBiT}$ reporter followed by treatment with urolithin $\mathrm{A}(2.5-10 \mu \mathrm{M})$ resulted in an increase in reporter activity as measured by luminescence (B). Values are mean \pm SEM for at least 3 independent experiments (ns: not significant; ${ }^{*} p<0.05$; ${ }^{* *} p<0.01 ;{ }^{* * *} p<0.001$, compared with untreated control; one-way ANOVA with post-hoc Tukey test).

\section{Figure 11}

Reversal of neuroprotection by urolithin $\mathrm{A}(10 \mu \mathrm{M})$ in APPSwe-transfected ReNcell VM human neural stem cells in the presence of chloroquine (40 $\mu \mathrm{M})$ was measured with MTT $(A)$ and LDH $(B)$ assays. Values are mean \pm SEM for at least 3 independent experiments $\left({ }^{* * *} p<0.001\right.$; compared with untreated cells.

${ }^{\theta \theta \theta} p<0.001$, compared with APPSwe control. ${ }^{\&} p<<0.01 ; \& \& \& p<0.001$, compared with urolithin A + APPSwe control; one-way ANOVA with post-hoc Tukey test).

\section{Supplementary Figure 1 (S1)}

Immunofluorescence detection of nestin in undifferentiated ReNcell VM human neural stem cells.

\section{Supplementary Figure 2 (S2)}

Immunofluorescence detection of $\beta$ III tubulin in differentiated ReNcell VM human neural stem cells.

\section{Supplementary Figure 3 (S3)}

Immunofluorescence detection of MAP2 in differentiated ReNcell VM human neural stem cells.

\section{Supplementary Figure 4 (S4)}

Treatment of BV2 microglia with urolithin $A(2.5-10 \mu \mathrm{M})$, followed by stimulation with LPS $(100 \mathrm{ng} / \mathrm{ml})$ for $24 \mathrm{~h}$ did not affect cell viability as determined by MTT viability assay.

\section{Supplementary Figure 5 (S5)}


Immunofluorescent analyses showing that pre-treatment with urolithin A (2.5$10 \mu \mathrm{M}$ ) resulted in inhibition of nuclear accumulation of NF-kB p65 sub-unit (A) and acetylation (B) in BV2 microglia stimulated with LPS (100 $\mathrm{ng} / \mathrm{ml})$ for $60 \mathrm{~min}$. Supplementary Figure 6 (S6) Immunoflurescent detection of SIRT-1 protein following treatment of BV2 microglia with urolithin $\mathrm{A}(2.5-10 \mu \mathrm{M})$.

Supplementary Figure 7 (S7) Immunofluorescence showing SIRT-1-dependent inhibition of nuclear localisation of NF- $\mathrm{KB}$ in LPS-stimulated BV2 microglia by urolithin A. 


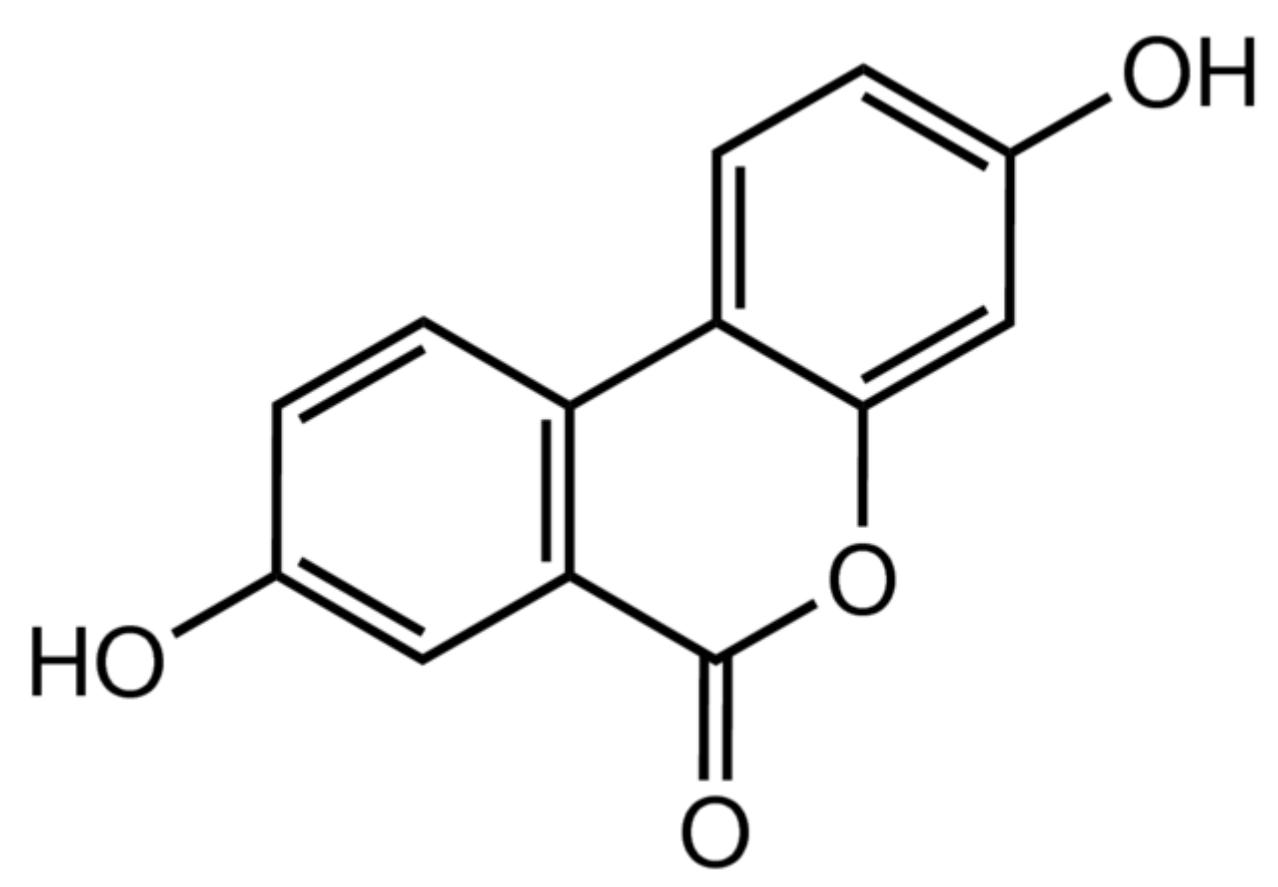


A

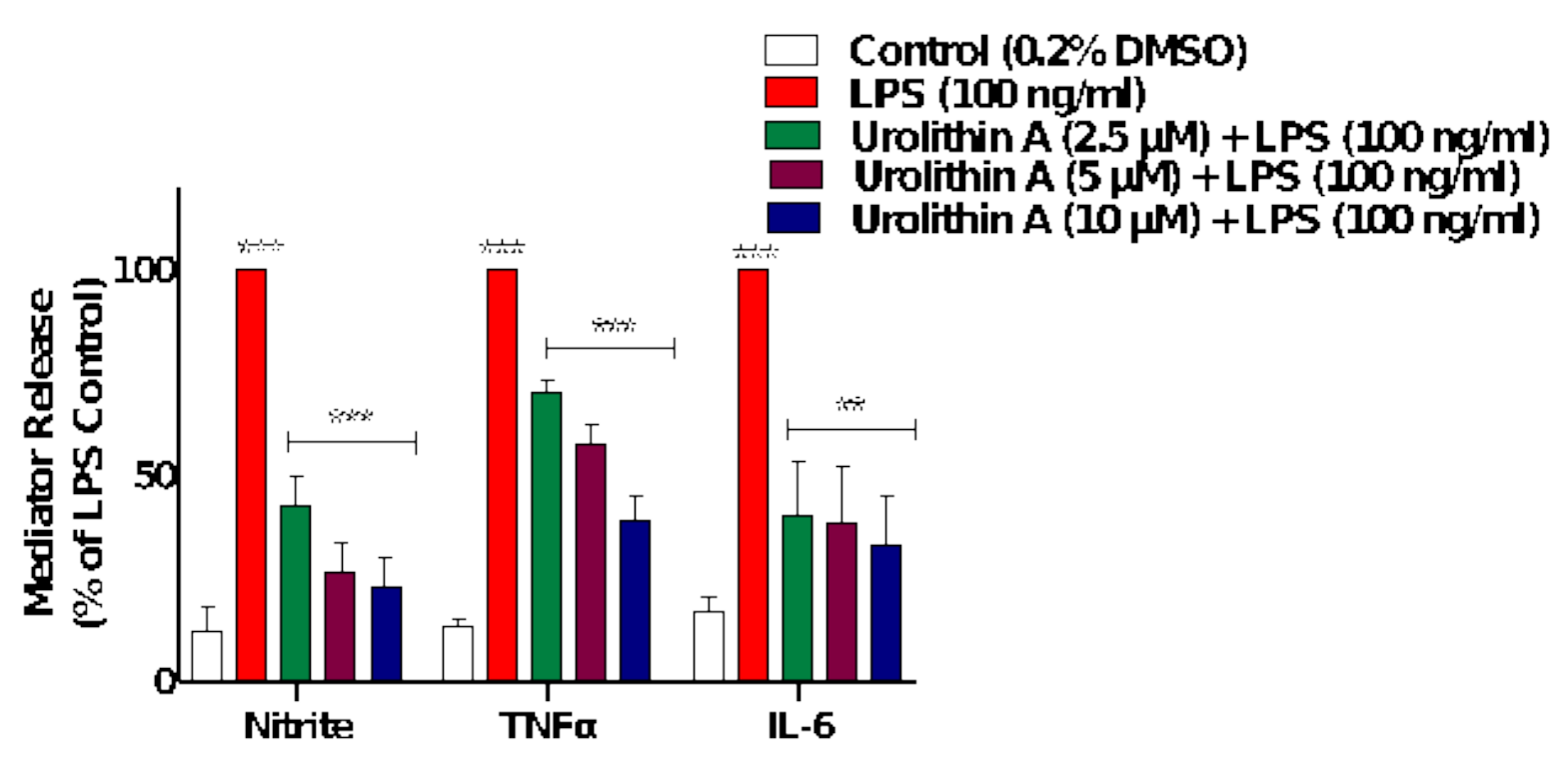


B

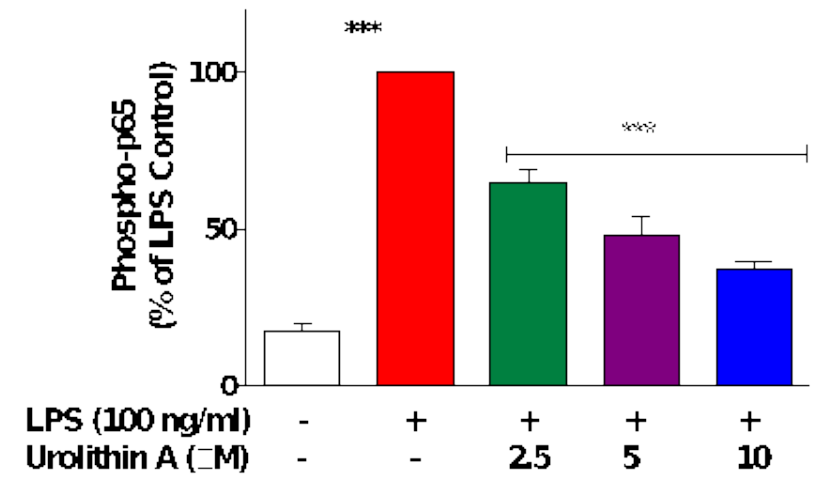

C

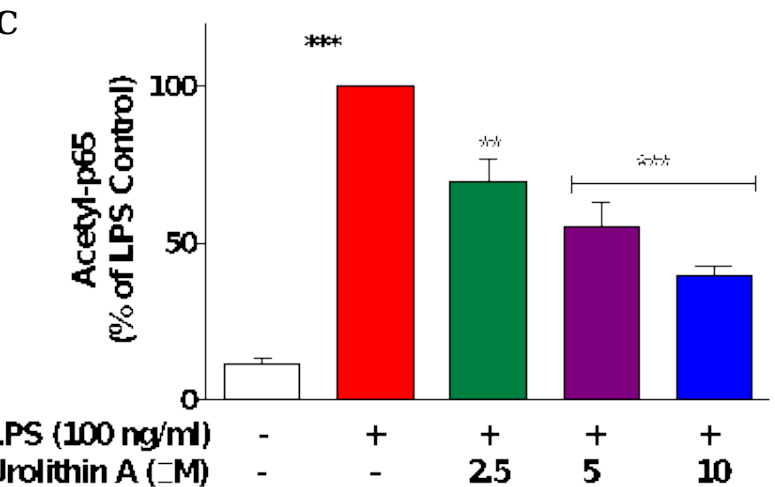


A

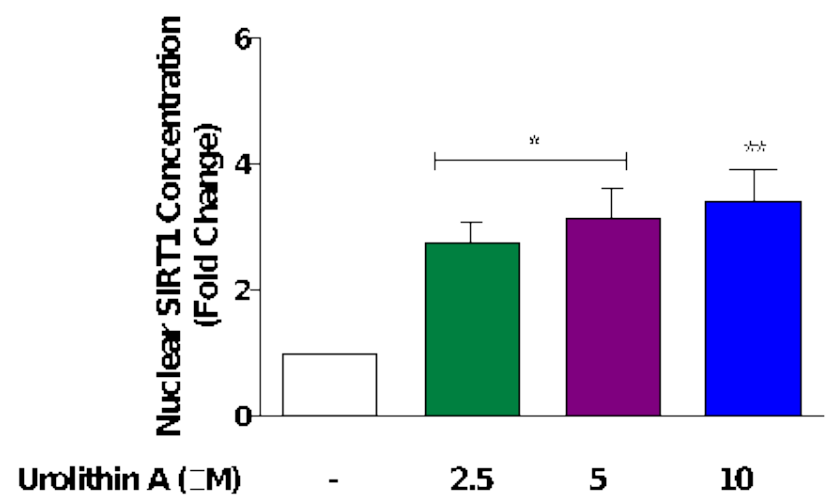

B

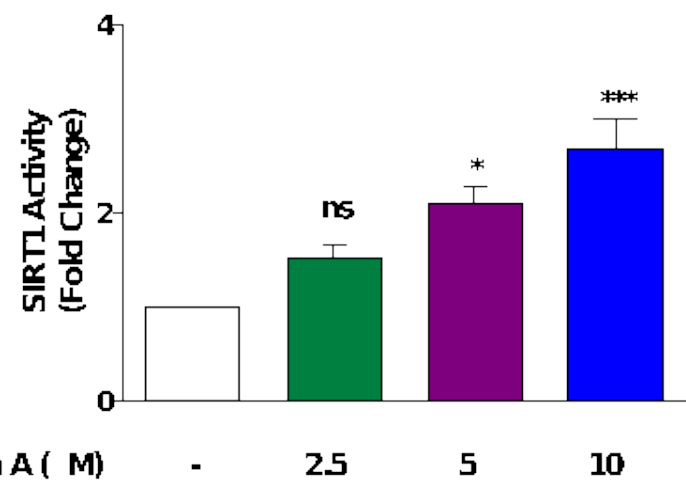


Control (0.2\% DMSO)

LPS $(100 \mathrm{ng} / \mathrm{ml})$

Urolithin A (10 $\mu \mathrm{M})+$ LPS (100 ng/m)

EX527 $(1 \mu \mathrm{M})+$ Urolittin A $(10 \mu \mathrm{M})+$ LPS $(100 \mathrm{ng} / \mathrm{ml})$

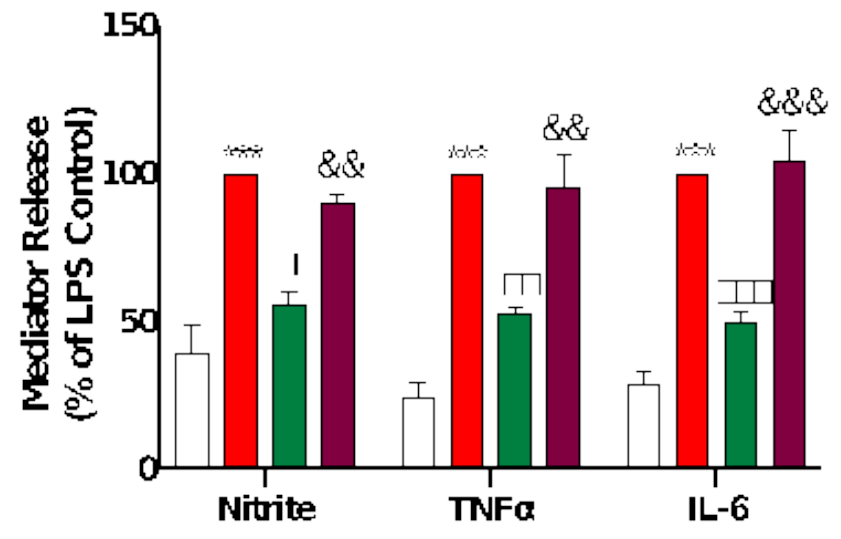


A
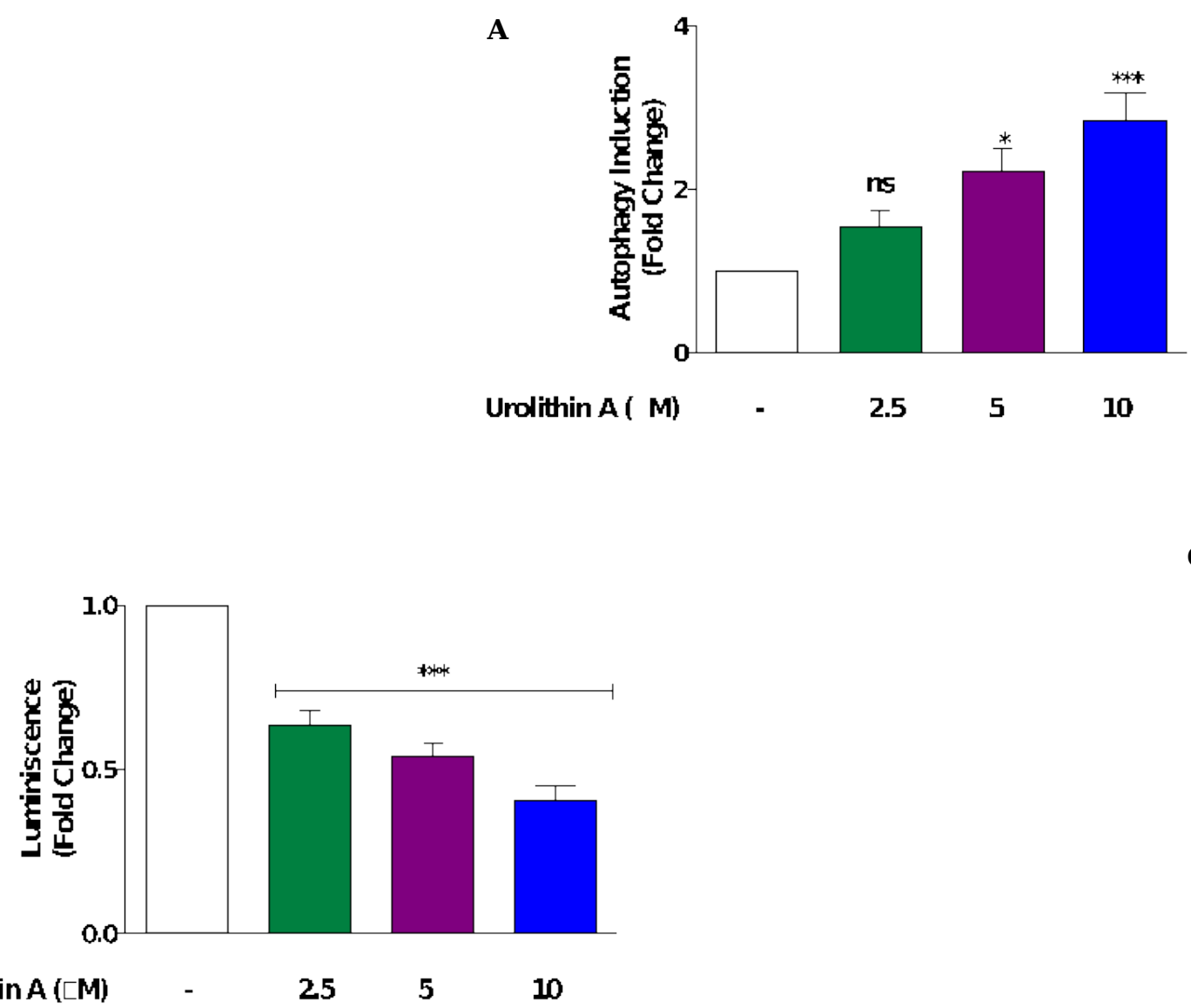

C

${ }_{5}^{4}$ Figure 5

6

9

10

11

13

14

16

17

18

19

21

23

24

26

27

28

29

30

31

32

पर

38

39

40
41

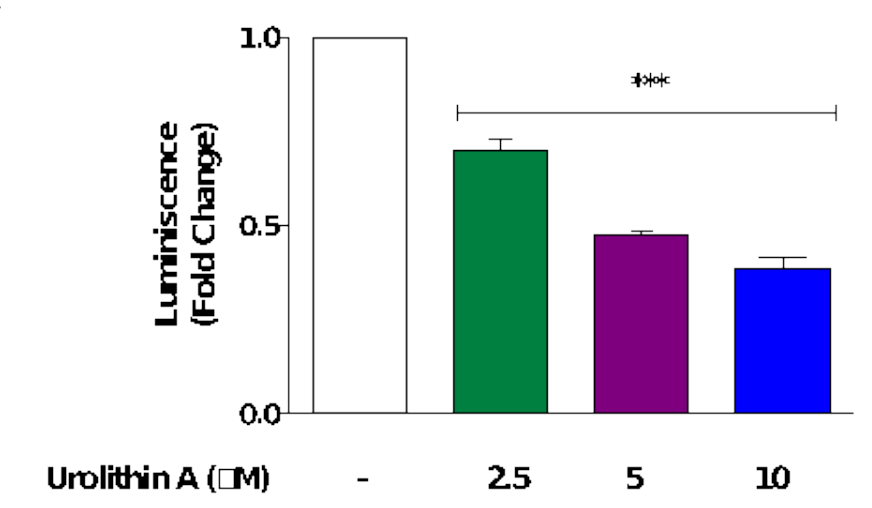



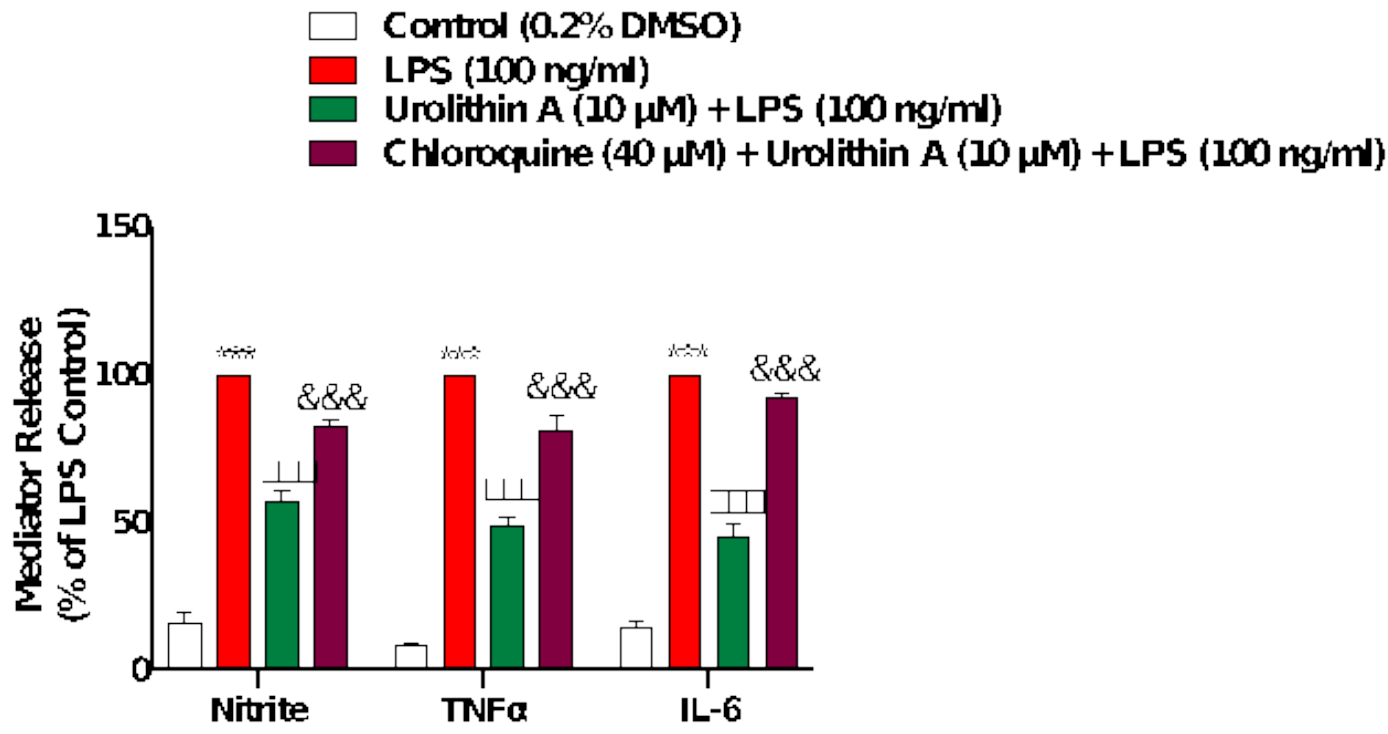

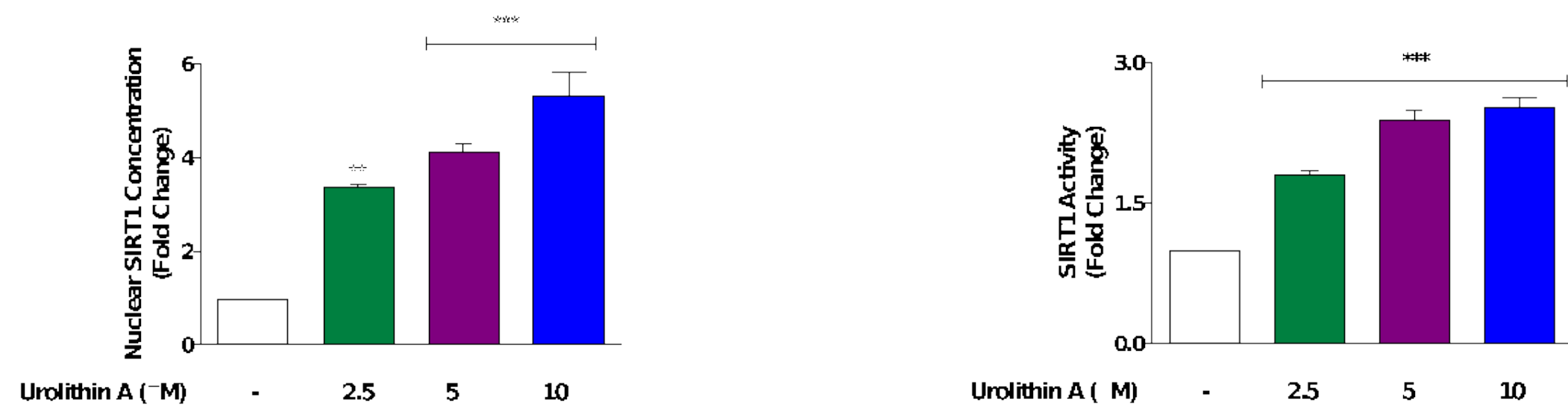


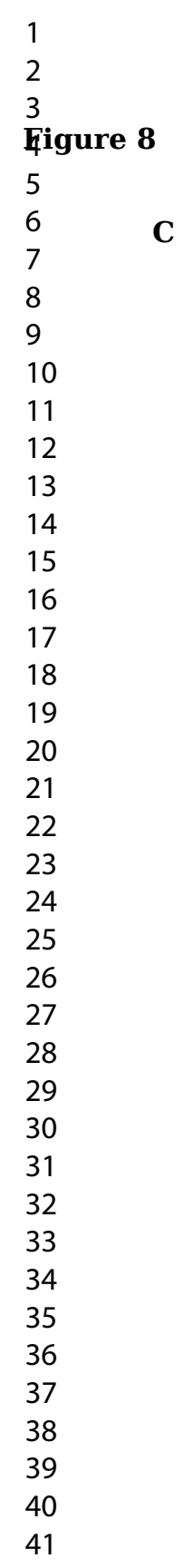

Urolithin A $(\mu \mathrm{M})$
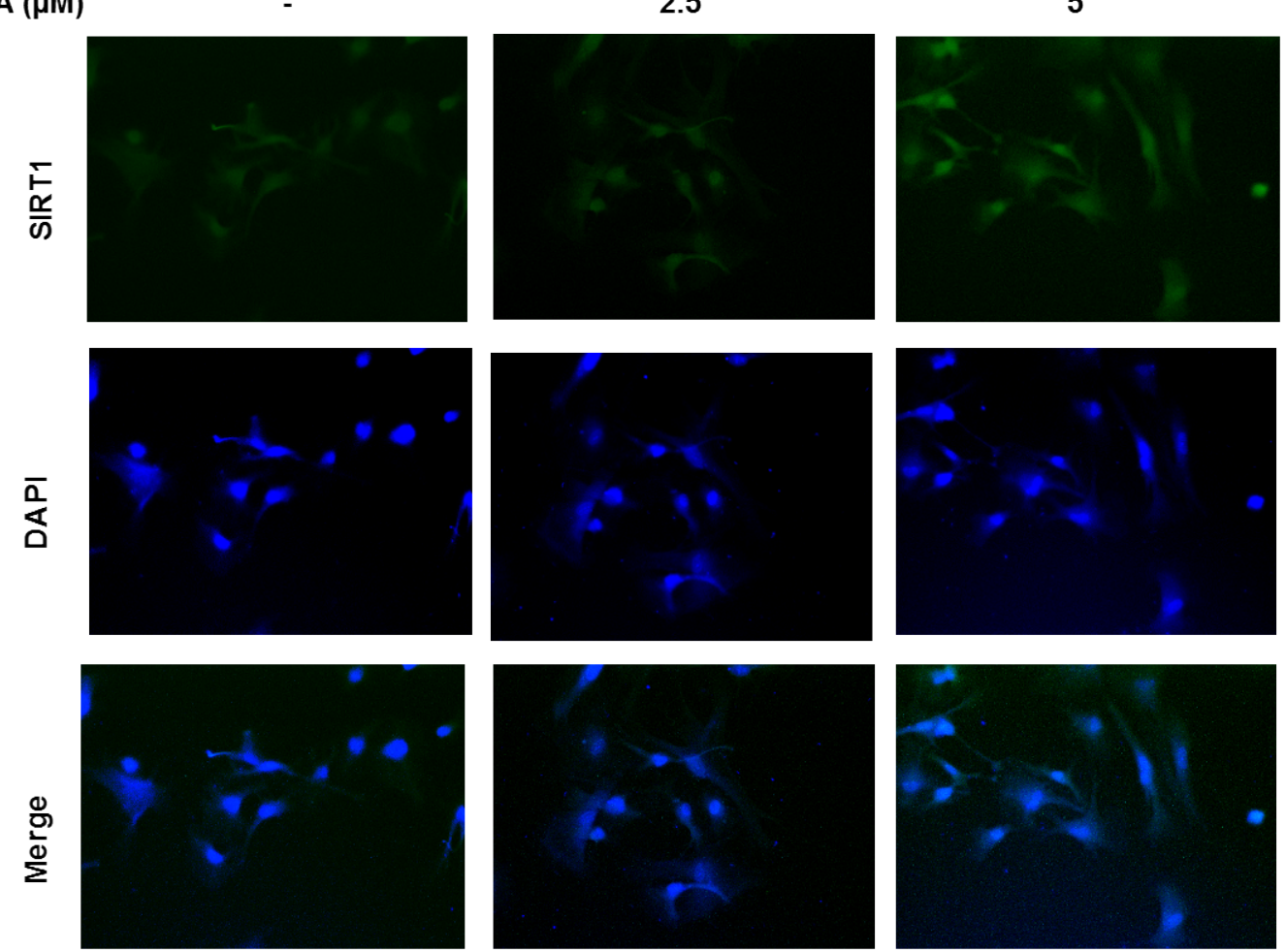

10
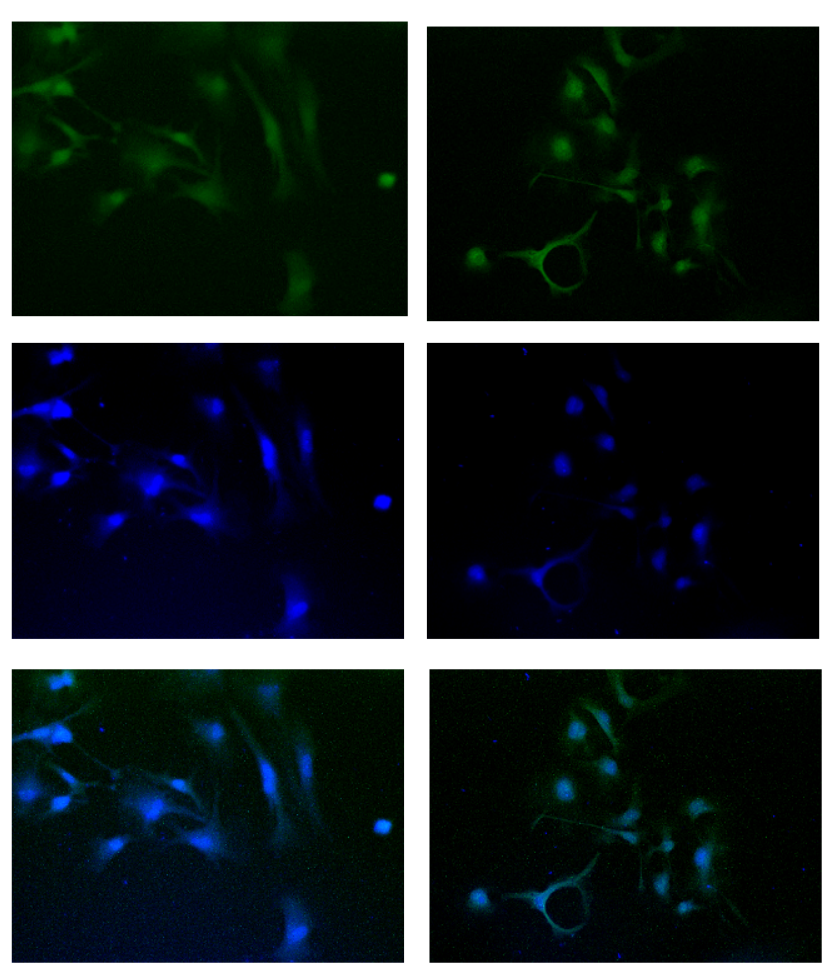

$\mid$ 
A

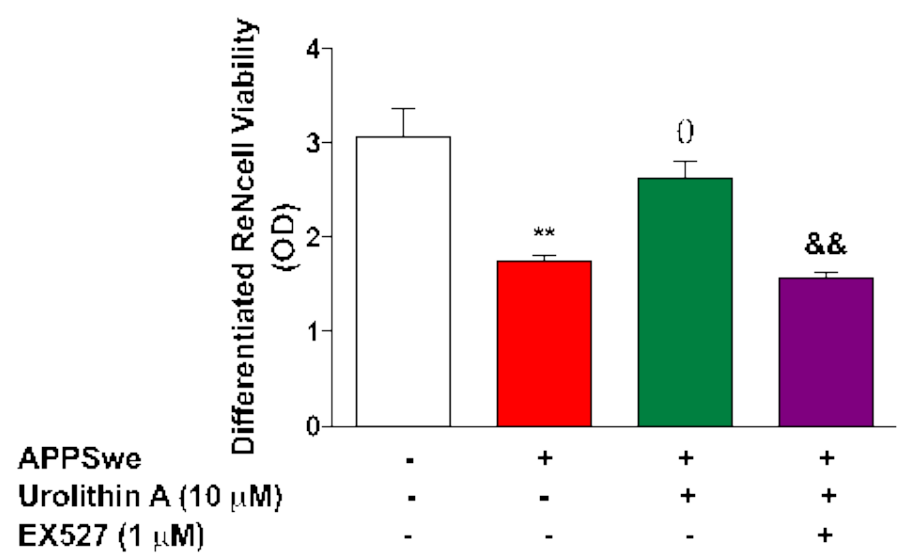

B

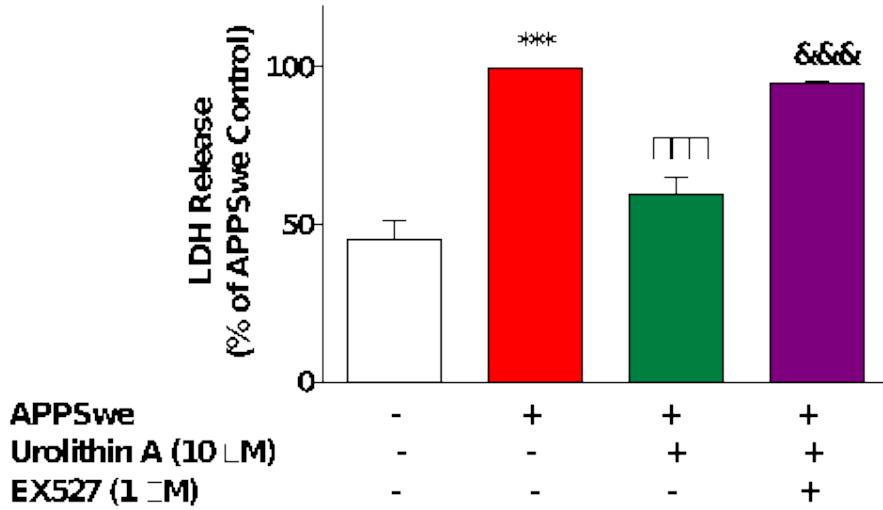


A

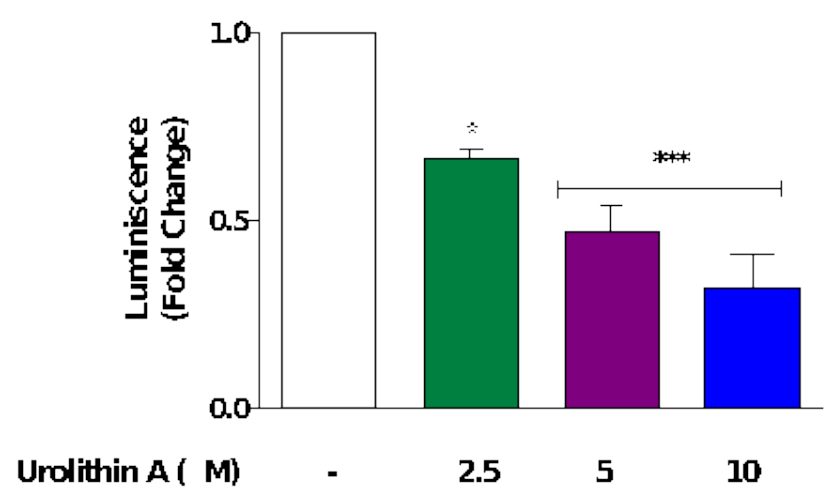

B

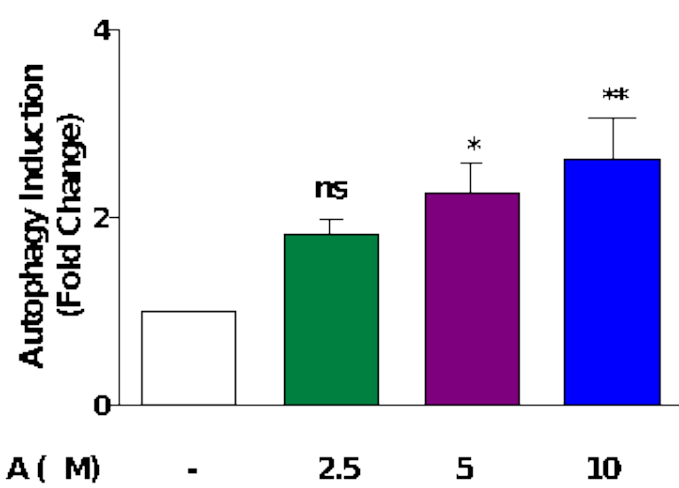


A

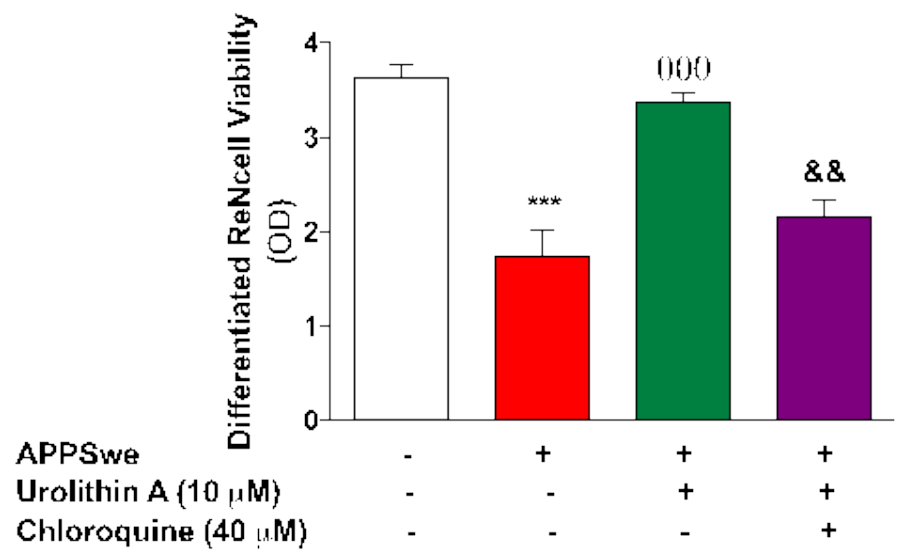

B

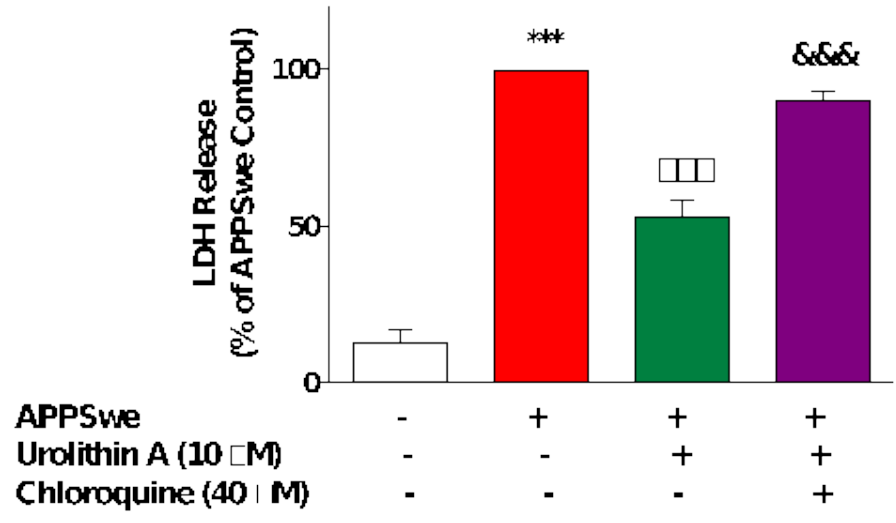

